\title{
REDES DE PROJETO PARA SUSTENTABILIDADE: UMA REFLEXÃO SOBRE O CASO DA EMPRESA VUELO
}

Roberto Zimmer Araujo

PPG Design Unisinos

rzaraujo@unisinos.br

Karine de Mello Freire

PPG Design Unisinos

kmfreire@unisinos.br

Resumo: Este artigo consiste num estudo exploratório em relação a formas de contribuição da lógica de redes de projeto em design estratégico para sustentabilidade. Para tanto, além de revisão teórica, foi analisado o caso da empresa Vuelo, uma empresa de bolsas, mochilas e acessórios para viagem que opera a partir de uma cultura de projeto fundamentada em valores sustentáveis. As relações ecossistêmicas estabelecidas pelo modelo de negócio projetado pela Vuelo permitem a disseminação dos valores sustentáveis fundamentais da empresa, cocriados seguindo a lógica de constelação de valores. Uma evidência dessa disseminação está na atitude dos vuelistas (identidade do usuário da Vuelo), que buscaram a empresa na ocasião em que um produto da linha apresentou problemas de fabricação. A empresa desenvolveu um projeto em rede articulando usuários, fabricantes e uma universidade com o objetivo de alterar o processo de fabricação de tal forma que o problema fosse solucionado. Neste projeto, se destaca o processo de troca de informação entre a Vuelo e os outros atores e a complementariedade de conhecimento. As principais contribuições do caso são no sentido da disseminação dos valores sustentáveis assumidos pela empresa a partir das relações com outros atores, a consciência em relação aos impactos sociais e ambientais nos usuários e a relevância da diversidade de informações provenientes de atores diversos de uma rede de projeto.

Palavras-chave: Design estratégico, redes de projeto, sustentabilidade, constelação de valor, Vuelo.

Abstract: This paper is an exploratory study bout ways of contribution of networks project logic to strategic design for sustainability. Therefore, in addition of literature review, it was analyzed the case of the company Vuelo, a company of bags, backpacks and accessories for travel that operates from a design culture based on sustainable values. Ecosystemic relations stablished by the business model designed by Vuelo allow the spread of the sustainable core values of the company, cocreated from the 
logic of value constellation. An evidence of this spread is the attitude of vuelistas (identity of Vuelo's user), who sought the company at the time that a product line presented manufacturing problems. The company developed a network project articulating users, manufactures and an university looking for a solution. On this project, there is rebounded the process of exchange of information among Vuelo and the other actors and the complementarity of knowledge. The main final considerations are towards the dissemination of the sustainable values assumed by the company through the relation with other actors, the awareness related to social and environmental impacts on users and the relevance of information diversity from the different actors in the project network.

Keywords: Strategic design, project networks, sustainability, value constellation, Vuelo.

\section{INTRODUÇÃO}

Denomina-se design estratégico a área de conhecimento na qual o design se relaciona a estratégia das organizações, e com isso a visão projetual transcende a instância do desenvolvimento de produto e se relaciona ao sistema produto-serviço, um conjunto que reúne produtos, serviços prestados e processos de comunicação (FRANZATO et al, 2015; FREIRE, 2015, MERONI, 2008). Zurlo (1999, apud Freire, 2015), apresenta o design estratégico como uma atividade de projeto na qual o objeto é a interface que a empresa exibe ao contexto social e mercadológico, ou seja, o modo pela qual ela formaliza a estratégia.

Franzato et al (2015) afirmam que o design estratégico enfatiza o estudo da estratégia no sentido da orientação da ação projetual, sobretudo as inciativas direcionadas à inovação e à sustentabilidade. Este processo envolve todo o ecossistema, ou seja, meio organizacional, mercado, sociedade e meio ambiente. Assim, pode-se compreender o design estratégico como uma área de conhecimento caracterizada por articular diferentes saberes na perspectiva da estratégia, da ação projetual, considerando o conjunto de relações descritas além da própria organização.

Neste contexto, importa comentar a relevância das relações ecossistêmicas que se estabelecem na atividade de projeto das organizações, e com isso a possibilidade de considerar a lógica de redes de projeto, com a participação de outros atores conectados pelo sistema. Uma vez que a dimensão projetual que aqui se refere não se limita ao produto, mas todo o sistema que o envolve, as relações da organização com o ecossistema são de análise relevante para compreender os processos de desenvolvimento em sua essência bem como o conjunto de valores que sustenta a prática que formaliza a estratégia.

Levando em consideração a característica apresentada há dois parágrafos, de que as iniciativas direcionadas à inovação e à sustentabilidade protagonizam um espaço de estudo nesta área, segundo Franzato et al (2015), nota-se a possibilidade de analisar processos de redes de projeto inovadoras fundamentadas em valores sustentáveis. Neste ponto apresenta-se o objetivo deste artigo, que é discutir formas de contribuição, na perspectiva do design estratégico, da lógica de redes em um 
projeto fundamentado em valores sustentáveis. Para tanto, será apresentado o caso da empresa Vuelo, fabricante de bolsas, mochilas e acessórios de viagem de Porto Alegre, no Rio Grande do Sul, que a partir da lógica de rede de projeto desenvolveu processos inovadores fundamentada em valores sustentáveis. Para realização deste artigo, além de revisão teórica também foram pesquisadas informações do site da empresa e realizada uma entrevista em profundidade com uma das sóciasproprietárias da Vuelo, denominada Sócia A.

\section{DESIGN ESTRATÉGICO PARA SUSTENTABILIDADE}

Resgatando a colocação de Franzato et al (2015), design estratégico enfatiza projetação em direção à inovação e a à sustentabilidade. Partindo disso, torna-se coerente apresentar a visão de sustentabilidade considerada neste artigo. Segundo a Comissão Mundial sobre Meio Ambiente e Desenvolvimento da Organização das Nações Unidas (1991), o termo sustentabilidade se refere a possibilidade de crescimento econômico fundamentado em práticas que conservem e expandam a base de recursos ambientais. Manzini e Vezzoli (2005) também colocam o princípio da equidade, na qual todas as gerações têm o mesmo direito a usufruir do mesmo espaço natural, e por isso a atitude ética do ser humano é no sentido da preservação das condições deste espaço.

Este conceito, originalmente muito vinculado à dimensão ecológica, passou a evoluir em função da verificação entre a forte relação entre problemas ambientais e sociais. Para tanto, é possível verificar a aplicação do conceito de sustentabilidade nas organizações segundo a visão de Elkington (2012): o triple bottom line, perspectiva na qual a sustentabilidade se compreende na relação entre crescimento econômico, justiça social e gerenciamento ambiental.

Manzini e Vezzoli (2005) colocam que o design pode colaborar para sustentabilidade em quatro níveis: (a) redesign de produtos já existentes, (b) projeto de novos produtos ou serviços que substituam os atuais, (c) projeto de novos sistemas produto-serviço intrinsicamente sustentáveis, e (d) proposta de novos cenários que correspondam a um estilo de vida sustentável. Este quarto nível é citado como o mais efetivo para longo prazo, uma vez que promove transformações culturais necessárias para sustentar um novo paradigma, por isso chama atenção a contribuição do design para construção de uma cultura de sustentabilidade.

Articulado a ideia deste quarto nível de colaboração do design para sustentabilidade, apresenta-se a ideia de Franzato et al (2015), que chamam atenção para as relações ecossistêmicas da organização que projeta, um elemento fundamental segundo a ótica do design estratégico. Nessa perspectiva o design não se ocupa apenas do desenvolvimento de um produto, mas sim de uma cultura de projeto que considera toda a perspectiva ecossistêmica (ou sistêmica), ou seja, as conexões com os atores bióticos (organismos vivos) e abióticos (energia e recursos sem vida) que se mantém em equilíbrio dinâmico e interagem entre si. Estudar as relações ecossistêmicas nas organizações torna possível compreender valores próprios da sustentabilidade presentes ao longo de todo o sistema produto-serviço projetado, considerando o compartilhamento destes valores com demais instituições, sejam elas organizações parceiras, fornecedores, varejistas, usuários, comunidades, recursos naturais, entre outros. 
A partir disso, dois merecem reflexão. O primeiro deles é um conjunto de valores próprios da sustentabilidade. Para construção de uma cultura sustentável, Malaguti (2009) enumera uma série de movimentos necessários de valores da cultura contemporânea fortemente associados ao consumo que devem dar lugar a este novo conjunto, de valores associados a sustentabilidade.

Na visão da autora (2009), o consumo no sentido predatório, destrutivo, que esgota os recursos disponíveis, deve dar lugar a um consumo baseado em cuidado e conservação, no qual existe mais espaço para o hábito da manutenção dos bens ao invés de uma mentalidade de rápida substituição. Da mesma forma, a valorização da história, da memória, das experiências e marcas acumuladas pelo tempo e pela durabilidade de bens passam a representar novos valores sustentáveis, substituindo uma mentalidade na qual o valor está no virgem, no novo e na eterna juventude. Nessa perspectiva, os valores fundamentais da sustentabilidade se relacionam a ampliação da experiência com os sentidos, novos usos para objetos, bem como respeito e valorização da diversidade e um amplo conceito de beleza, valorização do coletivo e do comunitário e da compreensão do luxo como atitude comprometida com uma causa, com coragem para rupturas e qualidade de vida, diferente do pensamento de ostentação e aparência. (MALAGUTI, 2009)

Refletindo acerca do quarto nível de colaboração do design para sustentabilidade de Manzini e Vezzoli (2005) e a perspectiva do design estratégico de Franzato et al (2015) e Meroni (2008), pode-se sugerir que a prática do designer deve considerar esse conjunto de valores na constituição de todo o sistema produto-serviço, ou seja, tanto no que se refere aos elementos que constituem o produto, processos relacionados, a proposta de valor, e também os hábitos que estimula.

É interessante observar este último elemento, os hábitos que estimula, pois neste artigo o sentido de contribuição para sustentabilidade a partir do design estratégico não se limita a escolha de matérias-primas que conservem recursos naturais, mas que não estimulem o usuário a refletir a respeito do impacto do consumo e o uso até o fim de sua vida útil. Ou seja, adquirir um produto reciclável neste contexto não é suficiente se não há uma compreensão da possibilidade de reduzir o volume de compra (mesmo que de produtos recicláveis ou reciclados).

O segundo ponto de reflexão é referente às relações que se estabelecem no sistema produto-serviço projetado. Ao sistema produto-serviço projetado por uma organização, ele se conecta a organizações parceiras, fornecedores, varejistas, usuários, recursos naturais, comunidades e outros, que passam a compartilhar os valores que o fundamental. Considerando o desenvolvimento projetual do sistema na lógica de rede, o conjunto de valores para sustentabilidade passa a ser compartilhado com os diversos atores conectados, o que contribui para sua disseminação, e contribuindo com isso para o estabelecimento de uma cultura sustentável. Nesse momento, cabe apresentar a teoria de empresa em rede de Castells (2009) que ilumina a lógica de organização em rede para projetação; a isto é dedicada a próxima seção deste artigo.

\section{REDES DE PROJETO E A CONSTELAÇÃO DE VALOR}

Uma das formas de projetar segundo o design estratégico é a partir de redes de projeto. Esta forma se constitui pelo desenvolvimento projetual que considera diferentes atores na medida em que avança. Existem diferentes formas de organização 
e formação destas redes, mas apesar disso, elas se caracterizam pelo compartilhamento de conhecimento e de valores fundamentais. Numa rede projetual, novas oportunidades são criadas a todo tempo e nas diferentes relações ecossistêmicas que se estabelecem.

A possibilidade de operação em rede permite que empresas de pequeno e médio porte se conectem entre si e também com empresas de maior porte a partir de novas tecnologias em contexto global (CASTELLS, 2009). Além disso, as redes permitem conexões com organizações além das empresariais, como comunidades e organizações sociais diversas, bem como usuários, especialistas, pessoas diversas com a intenção de colaborar, e assim por diante. Nesse sentido, é interessante colocar a perspectiva de Levy (2011), na qual a ocasião da conexão entre dois ou mais diferentes atores se assume que cada um possui um conhecimento diferente, e por esse motivo sempre é possível estabelecer uma relação de aprendizado. Dessa forma, é possível compreender que a operação em rede permite às diferentes organizações aprenderem a partir dessas relações. Este aprendizado pode acontecer tanto em níveis mais superficiais, como a aplicação de uma nova tecnologia, quando mais profundos, tais como de sistemas de valores fundamentais.

Levy (2011) também coloca o ato do uso como projeto. Em sua perspectiva, o uso é um prolongamento da tendência já delineada pelas interpretações anteriores, ou ainda a construção de novos ordenamentos de sentido. Ao passo que os usuários usam, eles também criam, e com isso uso e criação são dimensões próximas, ou até mesmo sobrepostos ou difusos. Na relação do projeto com o usuário, portanto, tanto se tem possibilidade criativa, quanto de compartilhamento e difusão de valores. Ao articular este pensamento com o design para sustentabilidade, essa relação é fértil para nova consciência do usuário em relação ao sistema produto-serviço, adoção de novos hábitos e a compreensão de propostas de valor que tenham elementos sustentáveis em sua base.

Neste ponto, importa comentar a teoria apresentada por Normann e Ramírez (1993) sobre constelação de valor. Segundo os autores (1993) a criação de valor deve transcender a lógica de uma cadeia produtiva que beneficia produtos na qual cada um é responsável por seu papel isolado neste sistema. Os diferentes atores fornecedores, parceiros de negócios, aliados, consumidores, entre outros - devem trabalhar juntos para coproduzirem valor. A chave da estratégia nesta teoria está na reorganização dos papéis e relações entre a constelação de atores do ecossistema que se relacionam para criação de valor em novas formas.

A rede, portanto, é um maio pelo qual se pode formar uma constelação de valor a partir de arranjos que aproximem fornecedores e consumidores, empregados e gerentes, equipes técnicas e administrativas, e assim por diante. Com isso, é possível não gerar apenas um produto, mas sim um conjunto de serviços, produtos, projetos, gerenciamento e suporte que tragam em si a constelação de valores (NORMANN; RAMÍREZ, 1993).

\section{O CASO DA EMPRESA VUELO}

A Vuelo é uma microempresa brasileira, localizada em Porto Alegre, no Rio Grande do Sul, em atividade desde 2013. É uma organização empresarial no ramo de couro, calçado e artefatos, especificamente da classe de fabricação de artigos para viagem, bolsas e semelhantes de qualquer material. Os principais produtos ofertados 
pela organização são mochilas, bolsas de viagem e outros artigos relacionados, alguns deles representados na figura 1. (VUELO, 2015)

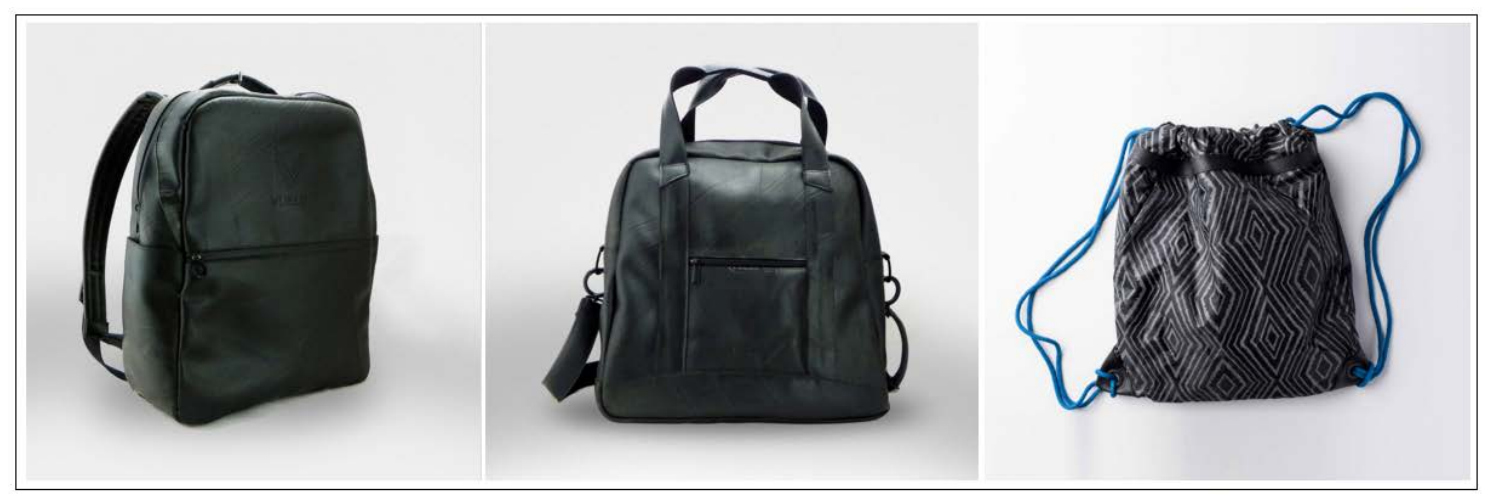

Figura 1: Exemplo de produtos Vuelo: Mochila, Weekend bag e Mochila casca. Fonte: Vuelo (2015)

A Vuelo foi constituída a partir do objetivo das duas sócias em aliar a atividade profissional a hábitos sustentáveis que já tinham em seu cotidiano, como separação de lixo e encaminhamento a reciclagem. A partir da ideia da Sócia A em desenvolver uma bolsa de viagens e da Sócia $B$ em projetá-la de forma totalmente sustentável nasceu a Vuelo. A cultura de design está na base da criação da empresa, com uma centralidade no objeto e nas virtudes estéticas e funcionais dos materiais, mas também com o olhar para o sistema e a rede de valor. O modelo de negócios da empresa foi projetado de modo a gerar produtos que tragam um novo sentido para a vida de seus consumidores a partir de conexão coletiva, ou seja, uma rede que inclui recicladores, costureiras, modelistas, designers e artistas que reduz a distância entre quem cria e quem usa (VUELO, 2015).

Importa comentar que a empresa, embora tenha a característica da cultura de projeto, não opera com clareza do conceito de design estratégico, no entanto a análise que aqui se faz parte deste ponto de vista. Desde a concepção da empresa, a Vuelo projetou um novo modelo de negócios sustentável, a começar pelo sistema de fornecimento de matérias-primas e processos intermediários, até a produção de artefatos. Além disso, a partir de suas relações ecossistêmicas, a Vuelo constituiu uma lógica de rede de projeto, uma possibilidade pela abordagem do design estratégico.

A projetação do sistema produto-serviço da Vuelo partiu da pesquisa de materiais que apresentassem características físicas de durabilidade e resistência para projetação da bolsa de viagem. Na câmara de pneus as sócias perceberam qualidades interessantes, que atendia tanto os requisitos estéticos e funcionais quanto a vinculação a ideia de sustentabilidade com o reaproveitamento de um material. Segundo a sócia $A$, as câmaras de pneu "se assemelhavam ao couro, além de ser emborrachada ainda, que tinha uma vantagem de ser a prova d'agua, e com um aspecto meio futurista", além de se constituírem num resíduo altamente poluente (leva cerca de 500 anos para decomposição na natureza). Com isso, foi definido o primeiro material de base para a bolsa, mesmo que fosse de difícil costura e por isso necessário desenvolver também um novo método para esta etapa de produção.

Definido este material, foram mapeadas e visitadas diferentes borracharias de Porto Alegre para desenvolver fornecedores, e com isso estabelecidas as primeiras 
relações com outros atores do ecossistema. Neste processo foi percebido que a câmara no pneu representa para as borracharias um resíduo sem utilidade: enquanto não é descartado gera um estoque desnecessário, e se descartado incorretamente gera problemas ambientais.

Este material representa uma escolha coerente com o pensamento da sustentabilidade para além da reciclagem, mas também nos valores fundamentais apresentados por Malaguti (2009). Por ser um material de alta resistência indica a relação com cuidado e conservação, além da valorização das marcas acumuladas pelo tempo na superfície das câmaras, que revelam a sua história, ampliando a experiência e articulando estes valores sustentáveis também à noção de exclusividade.

Durante o desenvolvimento dos protótipos da bolsa de viagens, foi percebida a necessidade de utilizar um forro no produto, por isso as sócias passaram a buscar uma alternativa de tecido reciclado como segunda matéria-prima. As sócias identificaram o náilon de guarda-chuvas descartados como possibilidade de material que atendesse tanto as especificidades técnicas quanto os princípios sustentáveis. Este é um tecido impermeável e resistente e em função do sortimento das estampas dos tecidos coletados, os produtos Vuelo apresentam diferentes forros, o que se articula mais uma vez à noção de exclusividade associada aos valores sustentáveis.

O fornecimento deste tecido acontece por meio de Unidades de triagem de Porto Alegre, que são cooperativas de catadores de lixo reciclável. Estas Unidades recolhem materiais recicláveis, separam e comercializam para organizações interessadas. A Sócia A relata que estas cooperativas trabalham na coleta apenas de materiais que existe encomenda para comercialização, sendo que o náilon do guardachuva não era um material até então utilizado. A partir dessa nova necessidade, portanto, as Unidades de triagem passaram a recuperar um material que até então não tinha destino (e por isso permanecia em locais de destinação de lixo na cidade), e passa a ser uma nova alternativa de geração de renda.

O que é interessante comentar nesse momento, e que transcende a visão até então trazida por Castells (2009) e se articula a perspectiva de Normann e Ramírez (1993), é a de que a Vuelo, ao projetar este sistema, passa a disseminar seus valores fundamentais por meio da rede. A relação entre os diversos atores gerou um contexto no qual materiais que antes representavam problemas num sentido amplo (descarte indevido, não reciclagem), se tornam oportunidade de geração de renda para esses atores. Ao compreender os valores fundamentais da Vuelo, passam a manter os materiais com cuidado tal que não comprometa as possibilidades de aplicação; uma atitude que garante o fornecimento do produto e evita geração de resíduos. Dessa forma, é possível compreender que nesse sistema em rede se estabelece a constelação de valor por meio da qual a sustentabilidade é disseminada entre as relações ecossistêmicas (o consumo com cuidado, a conservação, a manutenção, os novos significados, a valorização da história do material, entre outros).

A Sócia A define o modelo de negócio desenvolvido pela Vuelo como cíclico. Ele parte do sistema de trânsito e da cadeia do lixo, posteriormente a higienização, linha de produção e em seguida disponibilização no mercado. Todo produto Vuelo disponibilizado ao mercado é acompanhado por uma tag que explica a origem da matéria-prima e informa que no momento que os usuários, decidirem descartá-lo devem reencaminhar a peça à fabricante para que esta possa dar o destino adequado a seus componentes, o que inclui o encaminhando dos resíduos da borracha da câmara 
num processo de fabricação de asfalto ecológico, e com isso nova inserção do material no sistema de trânsito.

Neste ponto, se percebe a inclusão do usuário como um ator da rede capaz de projetar. Resgatando Levy (2011), o uso é uma extensão do projeto, a continuidade do intuído por outros atores e uma possibilidade de novo ordenamento de sentido. A fase de uso dentro da complexidade do sistema produto-serviço projetado, traduz alguns dos principais elementos na tag que acompanha o produto propriamente dito para disseminar a informação ao usuário, fazê-lo consciente de uma base de valores sustentáveis sobre o qual este sistema se estabelece.

O que se pretende é que o usuário de fato use o produto por todo tempo de vida útil, de tal forma que não finde o uso prematuramente por razão outra que não seja seu desgaste, e que no momento de descarte o usuário dê o encaminhamento correto ao material. No entanto, a atitude do usuário pode ser no caminho da subversão da orientação, da construção de um novo rumo, ou até mesmo de desconsiderar informações recebidas pela tag, o que se articula a perspectiva dos novos ordenamentos de sentido.

Há um outro elemento relevante na fase do uso. A Vuelo denomina seus usuários como "vuelistas", uma identidade àquele que não apenas adquire um produto, mas está apto a fazer parte de um sistema que o torna mais próximo a quem idealiza o produto e o confecciona (VUELO, 2015) e toma consciência das relações ecológicas e sociais envolvidas na produção do artefato. Com isso, a empresa amplia a experiência com um novo sentido para o objeto agregado pela consciência do sistema a que se conecta, o que representa um valor da cultura sustentável.

A postura dos usuários é um ponto interessante no caso. A identidade do vuelista preconiza a consciência dos valores sustentáveis relacionados do sistema produto-serviço e maior consciência em relação aos impactos sociais e ambientais do uso. Uma evidência de que que estes valores passaram a ser compreendidos pelos vuelistas é a comunicação estabelecida por parte destes indivíduos a empresa no momento em que um produto passou a apresentar problemas técnicos nos produtos. A Sócia A relatou que em função das especificidades técnicas da câmara de pneu, surgiram alguns problemas relacionados a costura das mochilas comercializadas. A atitude do vuelista de buscar diálogo com a fabricante para buscar alternativas ao problema ao invés do descarte representa a consciência em relação ao impacto do uso, o que contrapõe uma postura de descarte prematura articulada a lógica dos valores fundamentais da cultura de consumo.

Os testes de costura na câmara que haviam sido realizadas durante o desenvolvimento projetual não haviam sido suficientes para prever todas as possibilidades de aplicação possíveis do artefato, e algumas não previstas resultaram no problema da costura. A esta situação pode se articular a visão de Levy (2011), da continuidade do projeto na dimensão do uso, sendo uso e criação patamares próximos, sobrepostos ou difusos. A diversidade de formas de uso praticada pelos vuelistas submeteu o produto a determinada situação que a costura se mostrou indevida e ocorreram rasgos na câmara reaproveitada.

Com o objetivo de alterar o processo de produção da mochila para resolver os problemas técnicos relatados, a Vuelo iniciou um projeto em rede partindo da conexão entre a fabricante, os vuelistas e uma universidade. Dessa forma, a Vuelo passou a estruturar uma rede de projeto que articulava os diversos atores para gerar uma 
inovação incremental de processo, ou seja, alterar o processo de costura de tal forma que atendesse aos novos requisitos.

$\mathrm{Na}$ perspectiva de Levy (2011), cada indivíduo possui um conhecimento diferenciado dos demais e a partir de cada conexão é possível estabelecer relação de aprendizado. A fabricante das câmaras de pneus pode colaborar com um grande conjunto de informações técnicas em relação ao produto, sua composição química, processos de fabricação e assim por diante. Em relação aos vuelistas, tem a possibilidade de contribuir com informações referentes ao contexto de uso e relatos detalhados das situações em que o problema surgiu, como foi observado, ponto de origem do rasgo, tempo de início de manifestação do problema e velocidade de avanço, e assim por diante. Já a universidade proporciona a conexão da Vuelo a um contexto de discussão com estudantes de Design, que ao debaterem essa situação em projeto experimental expuseram o caso a diferentes formas processuais e projetuais de pensar, com diferentes repertórios, além de uma infraestrutura adequada a formação profissional, que contém equipamentos diversos para prototipação e testes. Essas diferentes conexões permitiram a Vuelo o acesso a uma maior base de informações, e o projeto desenvolvido em rede passa a considerar o conhecimento dessas diferentes fontes de forma complementar na direção de uma solução inovadora.

Normann e Ramírez (1993) colocam que na lógica da constelação não fica somente a cargo da organização a entrega de valor ao consumidor, mas sim o consumidor tem a possibilidade de estender a experiência com tamanha profundidade que passam a colaborar na sua criação. Uma vez que o usuário é compreendido como um ator e percebe-se nele a contribuição para criação de valor, evidencia-se que os valores sustentáveis idealizados pela Vuelo estão, de fato, sendo disseminados a partir das relações ecossistêmicas na rede.

Neste caso, após a proposição da solução adequada, com um processo de costura que atendesse os requisitos estabelecidos. Resolvido o problema, a rede de projeto cujo objetivo específico era a alteração no processo produtivo para resolução de um problema técnico, finda. No entanto, as relações ecossistêmicas da Vuelo com borracharias, unidades de triagem, fabricantes de câmara de pneus, vuelistas, universidade e outros permanece. Como colocam Normann e Ramírez (1993) a lógica da constelação de valores promove design e redesign constantes do sistema, e por isso essas relações são férteis para criação. Nesse sentido, a constelação se apresenta proporciona um fenômeno de constante criação de valores ao longo do sistema produto-serviço, proporcionando a disseminação de valores sustentáveis por meio das relações ecossistemas da organização pesquisada.

\section{CONSIDERAÇÕES FINAIS}

A partir da revisão apresentada, pode-se perceber formas de contribuição do design para construção de estratégias sustentáveis nas organizações. A perspectiva de projetação rede pela qual trabalha o design estratégico é capaz não só de estimular a projetação em função da fertilidade nas conexões entre atores, mas também disseminar os valores culturais a partir destas conexões.

Quando uma organização assume um determinado conjunto de valores e o traz a base de sua estratégia, passa a compartilhá-los com os diferentes atores do 
ecossistema com quem se relaciona. Malaguti (2009) apresenta um conjunto de valores fundamentais para cultura de sustentabilidade e a partir da projetação em rede, que ao serem considerados por uma organização passam a ser disseminados por meio das conexões em rede ao longo do desenvolvimento projetual.

No caso apresentado, a empresa Vuelo evidencia em sua estratégia valores fundamentais para cultura de sustentabilidade propostos por Malaguti (2009), como o cuidado e a conservação, a experiência ampliada e a valorização da história e marcas do tempo. Esses valores estão na base do desenvolvimento projetual desde o princípio, uma vez que partiu do objetivo de contribuir com a cadeia do lixo e promover consciência em relação aos diferentes impactos sociais e ambientais.

O caso da falha técnica na costura, que gerou o rasgo na mochila é um caso relevante de discussão, em primeiro lugar, por evidenciar a compreensão dos usuários valores fundamentais da sustentabilidade assumidos pela Vuelo. A tag com informações e a aproximação entre quem produz e quem usa gera consciência em relação aos impactos de tal forma que os usuários, ao perceberem o problema, tomam a atitude de buscar a Vuelo para não só buscar manutenção ao invés do descarte, mas também em colaborar para investigação de causas e contribuir com o desenvolvimento de um novo processo.

Embora a lógica da constelação de valor apresentada por Normann e Ramírez (1993) inclua os diversos atores que se relacionam com a empresa, ele dá destaque a participação do usuário. O caso da Vuelo tem essa participação evidente, tanto na atitude em procurar a fabricante para manutenção ou semelhante, quanto na participação posterior na atividade de projeto para gerar novo processo de costura da mochila e a construção de uma identidade, o vuelista, que contém os valores disseminados pela Vuelo a partir da rede.

Os usuários, assim como os demais atores relacionados, compartilharam conhecimento na rede de projeto, contexto na qual se complementavam, alimentando o conhecimento da rede enquanto coletivo. Ao mesmo tempo, os atores cocriavam os valores em constelação a partir das diferentes posições no sistema, fundamentados na perspectiva sustentável. A partir do caso foi possível verificar como uma organização por meio de redes chegou a uma solução a partir do design estratégico disseminando valores sustentáveis. No entanto, mais do que isso, se identifica uma constelação de valores a partir da qual a sustentabilidade passa a ser disseminada entre as diferentes relações ecossistêmicas da Vuelo.

\section{REFERÊNCIAS}

CASTELLS, Manuel. A sociedade em rede. São Paulo: Paz e Terra, 2009.

COMISSÃO MUNDIAL SOBRE MEIO AMBIENTE E DESENVOLVIMENTO (CMMAD). Nosso futuro comum. Rio de Janeiro: Editora da Fundação Getúlio Vargas, 1991.

ELKINGTON, John. Sustentabilidade : canibais com garfo e faca. São Paulo: M.Books, 2012.

FRANZATO, Carlo; DEL GAUDIO, Chiara; PARODE, Fábio; BENTZ, lone; BORBA Gustavo; FREIRE, Karine de Mello. Inovação Cultural e Social: design estratégico e ecossistemas criativos. In: FREIRE, Karine de Mello. (org.). Design Estratégico para a Inovação Cultural e Social. São Paulo, Kazuá, 2015, p. 157-182. 
FREIRE, Karine de Mello. Design estratégico para a inovação social. In: FREIRE, Karine de Mello. (Org.) Design estratégico para inovação cultural e social. 1 ed. São Paulo: Editora Kazuá, 2015.

LEVY, Pierre. A inteligência coletiva: para uma antropologia do ciberespaço. São Paulo: Edições Loyola, 2011.

MALAGUTI, Cynthia. Design e valores materializados: cultura, ética e sustentabilidade. In: DE MORAES, Dijon. KRUKEN, Lia. (Org.) Cadernos de estudos avançados em Design: Sustentabilidade I. Barbacena: Editora da Universidade do Estado de Minas Gerais, v.a, 2009. Disponível em http://www.tcdesign.uemg.br/pdf/Sustentabilidade_I.pdf

MANZINI, Ezio. VEZZOLI, Carlo. O desenvolvimento de produtos sustentáveis. 1a ed. 1a reimpressão. São Paulo: Editora da Universidade de São Paulo, 2005.

MERONI, Anna. Strategic design: where are we now? Reflection around the foundations of a recent discipline. Strategic Design Research Journal, v.1, n.1, Dec 1, p.31-38. 2008.

NORMANN, R.; RAMíREZ, R. From Value Chain to Value Constellation: Designing Interactive Strategy. Harvard Business Review. N. 71, 1993. pp. 65-77.

VUELO. Projeto Vuelo. Disponível em http://store.vuelistas.com/projeto-vuelo/. Acesso em 08 de outubro de 2015. 